\title{
Una mirada al expansionismo estadunidense. La legación francesa en México, 1853-1860
}

Dolores Duval H.

IIH-UNAM

Este artículo plantea la percepción de la legación francesa en México sobre el expansionismo estadunidense durante el periodo de 1853 a 1860 , y aborda particularmente aquellos aspectos de las relaciones mexicano-estadunidenses que, según la legación, favorecían el fortalecimiento de Estados Unidos y disminuían la preponderancia europea en América. Asimismo, presenta la visión francesa sobre México que antecedió a la intervención napoleónica.

$A$ mediados del siglo XIX el expansionismo estadunidense era una realidad para los países de América Latina y Europa. En el caso de México, la amenaza de su vecino del norte constituye un capítulo importante de su historia. Estudios recientes en ambos países sobre las relaciones México-Estados Unidos utilizan enfoques y proporcionan informaciones novedosas, sin embargo poco se ha insistido en la percepción europea del asunto. ¿Cómo veían las potencias del viejo mundo la preponderancia que los estadunidenses estaban adquiriendo en América Latina? Con frecuencia se refiere el temor de dichos países europeos por su predominio en el continente americano, pero poco se ha puntualizado sobre cuáles eran los aspectos de dicho expansionismo que les preocupaban; asimismo, las versiones de acciones europeas para contrarrestarlo son imprecisas. Documentar la visión francesa sobre las ambiciones estadunidenses hacia México, los mecanismos y vías para su expansión, nos da una visión más completa de las relaciones México-Estados Unidos y México-Francia. En este ámbito se inscribe el presente trabajo, que abar. ca el periodo de 1853 a 1860 , el cual se inicia al establecerse el imperio de 
Napoleón III en Francia, y el gobierno de Antonio López de Santa Anna en México, ${ }^{1}$ y culmina previo a la intervención napoleónica en México. ${ }^{2}$ Eran años de gran inestabilidad económica y política para México, en los que Francia, al mando del recién nombrado emperador, Napoleón III, desarrollaba una política exterior de mayor agresividad en Europa (guerra de Crimea) y menos intensa en América. En ese contexto se analiza la postura de los tres ministros franceses encargados de la legación mexicana en dicho periodo: André Levasseur, Alphonse Dano y Alexis de Gabriac. ${ }^{3}$

¿De qué manera percibieron estos tres ministros el expansionismo de

\footnotetext{
'A pesar de que la instauración del imperio napoleónico (diciembre de 1852) y el inicio del gobierno de Santa Anna (abril de 1853) no coinciden en fechas, se puede decir que a mediados de 1853 las relaciones franco-mexicanas toman un giro peculiar debido a las tendencias políticas de ambos gobiernos. Sin embargo, el inicio del corte temporal se debe también a que los despachos de la legación que se tuvieron al alcance comienzan en 1853. Esta documentación se revisó en Diaz, Versión, 1963-1967.

${ }^{2}$ Cabe señalar que, aunque las tropas francesas llegaron a México en enero de 1862, el periodo del estudio concluye en 1860 . El fin de la guerra de los Tres Años; el rechazo del Tratado McLane-Ocampo por el Congreso de Estados Unidos, en 1860; los claros proyectos intervencionistas de Francia en México desde 1861, y el fin de la misión de Gabriac, son acontecimientos que cierran un capítulo de la historia de las relaciones franco-mexicanas.

${ }^{3}$ Sobre la vida de estos ministros hay poca información, pero vale la pena ubicar su posición en el contexto francés del momento y seguir su trayectoria política. Levasseur y Dano eran dos representantes que estuvieron ligados al proyecto de la república francesa (1850. 1852), en la cual el contrapeso de los liberales a las miras expansionistas de Luis Napoleón
}

Estados Unidos?, ¿cómo lo reflejaron a través de sus despachos al país galo?, ise puede develar en su correspondencia un plan monarquista e intervencionista en la década anterior a 1860?, ¿hasta dónde la amenaza estadunidense se percibió como una realidad en potencia y hasta dónde fue una bandera para justificar y fomentar la intervención francesa?, ¿en qué medida se mezclaron los intereses privados de esos ministros con la legación a fin de frenar las ambiciones de Estados Unidos en México?

Los despachos de los tres ministros ofrecen respuestas a estas preguntas, permiten apreciar cómo evolucionó la amenaza estadunidense en la percepción y en la actitud de la legación francesa en México, así como qué tanto las acciones de los representantes france-

definió una política exterior menos ofensiva que la que se desarrollaría durante el Segundo Imperio. En efecto, a los dos años de haberse nombrado emperador, Napoleón III hizo modificaciones en su gabinete, sustituyó a su ministro de Negocios Extranjeros, Drouyn de Lhuys, por el conde Alexandre. Walewski. Y en el caso mexicano, a finales de 1854 envió a México a Alexis de Gabriac como enviado extraordinario y ministro plenipotenciario (en adelante E.EMP), cuyos antecedentes de conocido monarquista, fervoroso católico y de extrema derecha, lo identificaban más con los planes del emperador. La periodización de los tres ministros a la cabeza de la legación es la siguiente: la misión de Levasseur como EEMP en México abarcó los años de 1849 a 1853. Dano, con importante trayectoria diplomática en América Latina, fue secretario de la legación con Levasseur y a la partida de éste se le nombró encargado de Negocios, cargo que ocupó de julio de 1853 a diciembre de 1854. Por su parte, Alexis de Gabriac fue EEMP de 1855 a 1860 . Barker, French, 1979, passim; Hanna y Hanna, Napoleón, 1973, passim; Díaz, Versión, 1963-1967, t. 1 y 2; Tulerand, $D i$ ctionnaire, 1995, p. 399. 
ses respondían a los lineamientos del gobierno imperial.

\section{EL MUNDO AMENAZADO}

La legación francesa basó su percepción del expansionismo estadunidense en los ámbitos comercial e industrial. A mediados del siglo XIX, el crecimiento de un competidor en América implicaba graves riesgos económicos y políticos para las potencias. Levasseur y Dano señalaban en sus escritos la riqueza comercial de las nuevas repúblicas hispanoamericanas y cómo las potencias europeas la regalaban a los "piratas modernos del nuevo mundo". "Sin embargo, fue Gabriac quien hizo consideraciones más profundas al respecto. Señalaba que Francia tenía importantes intereses económicos 5 y una considerable colonia de ciudadanos en México. ${ }^{6}$

\footnotetext{
${ }^{4}$ Dano al Ministerio de Asuntos Extranjeros de Francia (en adelante, MAEF), México, 1 de enero de 1854 en Díaz, Versión, 1963-1967, t. 1, p. 93 (en adelante se hará referencia a esta obra sólo con el apellido del compilador).

${ }^{5}$ Las relaciones comerciales entre Francia y México se vieron favorecidas por la presencia francesa en el país latinoamericano. A mediados del siglo $\mathrm{xIX}$ las exportaciones de Francia (textiles, pieles, papel y demás artículos suntuosos) al continente americano iban del $23 \%$ al $25 \%$ y se caracterizaban por tratarse de productos suntuosos y no industrializados, como sucedía con Inglaterra. En contraparte, Francia importaba de América Latina principalmente metales y materias primas. Se puede decir que el comercio con México no era de gran relevancia para el país galo, aunque estas cifras presentaron variaciones durante el periodo en cuestión. Meyer, Francia, 1992, pp. 201-205.

${ }^{6}$ La dimensión de la colonia francesa en México es incierta pero se puede decir con certeza
}

Por tanto, si Estados Unidos se apoderaba de México causaría graves daños a la economía mundial. ${ }^{7}$ Advertía así posibles consecuencias para Francia y el resto de las potencias europeas: 1) Pérdida de los mercados mexicanos para productos manufacturados en Europa (Francia e Inglaterra); 2) Ruptura de relaciones franco-estadunidenses y por tanto también el cierre de los mercados de Estados Unidos para Europa; ${ }^{8} 3$ ) Modificación del precio de los productos europeos en América por el control estadunidense de aranceles en el Golfo mexicano.

Por su parte, los beneficios que adquiriría Estados Unidos consistirian en: 1) Capitalización y crecimiento de su industria por la explotación de las minas mexicanas; 2) Crecimiento y monopolización de la industria en América; 3) La cancelación de México como competidor industrial y su transformación en proveedor de materias primas y consumidor exclusivo de productos inclustrializados por los estadunidenses; 4) Acumulación en manos estaduniden-

que, a mediados del xTx, era la segunda colonia extranjera más importante en México, después de la española, por su número (aproximadamente entre cinco y 7000000 pobladores) y actividades económicas (comerciantes, artesanos) e intelectuales (periodistas, maestros). Barker, French, 1979, pp. 126-131; Pérez, México, 1998, pp. 9-15; González, Extranjeros, 1993, t. 1, pp. 65-69.

${ }^{7}$ Gabriac al makf, México, 30 de encro de 1857, en Díaz, t. 1, pp. 384-385.

${ }^{8}$ Los nexos comerciales de Estados Unidos eran considerables para Francia. De $25 \%$ de sus exportaciones a América, $17 \%$ eran para la Unión, ponerlos en riesgo fue una preocupación del nuevo imperio napoleónico. Meyer, Francia, 1992, p. 201. 
ses de "gran cantidad de numerario" (oro de California y plata de México).

Gabriac resaltó también cómo estos problemas económicos tendrían efectos en otros ámbitos. En palabras suyas:

A cuestiones puramente materiales se relacionan las cuestiones políticas de una organización [estadunidense] demagógicamente activa, atrevida, turbulenta, que no retrocederá ante ningún obstáculo para trastornar a los gobiernos del viejo mundo y hacer triunfar sus doctrinas. ${ }^{9}$

Partiendo de esta percepción, Gabriac advertía que las ambiciones territoriales de Estados Unidos, satisfechas por medio de la compra, anexión o invasión, no se limitaban a la frontera norte de México (Sinaloa, Baja California y Sonora), sino que se expandían a Cuba y Yucatán, territorios que sumados a La Florida lo convertirían en el dueño de la "llave y el cerrojo" del Golfo mexicano. Consideraba que si algo había frenado a los estadunidenses era su "certidumbre" sobre los éxitos franceses en el Oriente, ${ }^{10}$ y el "temor" de una alianza anglo-francesa que decidiera controlar el "Atlántico como el Mar

\footnotetext{
${ }^{9}$ Gabriac al MaEF, México, 11 de mayo de 1858 en Díaz, t. 2, pp. 15-16. En este sentido recomienda que España e Inglaterra no provoquen conflictos con México a causa de sus re. clamaciones, ya que darían el pretexto perfecto para dejar a México en manos yanquis.

${ }^{10}$ Esta comparación se debe a que en la guerra de Crimea, Rusia pretendía ocupar Constantinopla, y Francia, junto con Gran Bretaña, trataba de impedir el expansionismo de dicha potencia hacia el Occidente. Pouthas, Politique, 1952, p. 68.
}

Negro". ${ }^{11}$ En este sentido, establecía de manera recurrente similitudes entre México y Constantinopla y entre Rusia y Estados Unidos, ${ }^{12}$ y señalaba la necesidad de difundir en América los logros militares de Francia contra el imperio de los zares a fin de demostrar su fortaleza como potencia mundial.

Por su situación geográfica (frontera sur de Estados Unidos, poseedor de la costa del Golfo de México y de un posible paso interoceánico) e importancia económica para cualquier potencia en vías de expansión, México representaba una pieza clave en lo que la legación llamó el "equilibrio americano". Equilibrio que ante un mundo en pleno crecimiento industrial y comercial resultaba indispensable conservar y controlar.

\section{LA SITUACIÓN MEXICANA}

Ia forma en que la legación francesa refería la situación interna mexicana iba más allá de la simple información de los hechos. Ésta era interpretada y manipulada por los encargados de la representación francesa con un objetivo: justificar la injerencia francesa en la política de México. En este punto, la correspondencia de los tres diplomáticos franceses es coincidente. En tono irónico, duro y hasta burlón se expresaron cons-

\footnotetext{
1 Gabriac al MaEf, México, 1 de enero de 1855 y 25 de enero de 1855 en Díaz, t. 1, pp. 159-163.

12 No obstante, percibía el sistema de gobierno y la situación interna de Estados Unidos inferiores a los de Rusia. Gabriac al MAFF, México, 6 de junio de 1855 en Díaz, t. 1, p. 189.
} 
tantemente de la incapacidad política de los mexicanos para gobernarse; del dominio del agio en las finanzas; de la ausencia de un hombre fuerte; del bandolerismo; de la eterna fiesta mexicana; de la mala herencia española; de la variedad de razas, entre otras peculiaridades.

Tres aspectos de esta realidad les preocupaban en relación con una posible anexión a Estados Unidos:

El primero se refería al sistema de gobierno. Los tres encargados de la legación advertían en el federalismo el sistema más propicio para el desmem. bramiento de México, ya que el descuido de grandes extensiones de territorio y la libertad política de los poderes locales (caciques y funcionarios) alentaba el deseo de independencia, favorecía su contacto con Estados Unidos y permitía la migración de ciudadanos de este país. En este sentido, se criticó a los republicanos federalistas por ser aliados políticos y promotores de las ambiciones de Estados Unidos en México. ${ }^{13}$ A pesar de estas ideas, Levasseur y Dano también criticaron a Santa Anna, ya que si bien éste parecía cumplir sus expectativas al plantear un gobierno fuerte y centralista, nunca supo controlar al país y su ambición de dinero y poder lo llevaron a celebrar tratados desventajosos para México. Esta opinión se acrecentó durante la guerra de los Tres Años, respecto de la cual Gabriac tomó abierto partido por el go-

\footnotetext{
${ }^{13}$ Luis de la Rosa fue al único personaje político mexicano que Gabriac reconoció positivamente por su acertada visión de Estados Unidos y sus ideas monarquistas. Gabriac al MAEF, México, 26 de junio de 1856 en Díaz, t.1, p. 312.
}

bierno conservador y contra el sector liberal que, según él, develó sus tendencias proestadunidenses con la firma del Tratado Mac Lane-Ocampo. ${ }^{14}$

El segundo aspecto abordaba la crisis económica mexicana. Los tres encargados de la legación apuntaban que la terrible necesidad de recursos de los sucesivos gobiernos para subsistir los obligaba a vender territorio o comprometerse con préstamos imposibles de pagar y respaldados con tierra mexicana, situación aprovechada por Estados Unidos y mecanismo mediante el cual se apoderaría de México paulatinamente, como ya había ocurrido.

El tercer punto consistía en la cuestión social y cultural. Los diplomáticos franceses apuntaban que las desdichas anteriores, aunadas al carácter débil y la falta de moral del pueblo mexicano, provocaba entre ciertos sectores el deseo de la ayuda estadunidense. Sin embargo, confiaban en que el antecedente monárquico y el sentimiento católico de la antigua colonia española impedirían que se estableciese un protectorado o se anexase gran parte de su territorio al vecino del norte, republicano $y$ protestante.

El tono imperante con el que se abordó la realidad mexicana parecía justificar la demanda, cada vez más imperiosa de la legación y de ciertos círculos de la sociedad mexicana, de una intervención europea.

Además de mencionar estos problemas internos, la legación reconoció otros aspectos que agudizaban la amenaza de Estados Unidos hacia México:

${ }^{14}$ Gabriac al MaEF, México, passim en Díaz, 
la frontera; la posible construcción de un paso interoceánico por Tehuantepec; la relación Iglesia-Estado, y la religión católica.

\section{LA FRONTERA}

A saber, la frontera era uno de los aspectos más conflictivos de la relación entre ambos países, pero según la legación, había tres problemas que resultaban particularmente escabrosos: los aventureros, los caciques y el Tratado de la Mesilla.

\section{Aventureros}

Los ministros galos abordaron este punto a través de dos casos: los nexos de Levasseur con el conde Gastón de Raousset de Boulbon y la visión de Gabriac sobre Santiago Vidaurri. ${ }^{15}$

Del primer caso, sabemos que Levasseur se interesó en el proyecto de colonización y explotación de minas en Sonora y que, junto con algunos políticos mexicanos y cónsules franceses, formó la Compañía Restauradora de la Mina de Arizona, la cual fue puesta en manos de Raousset, un ex político francés. Para algunos europeos y mexicanos la empresa parecía, en un principio, un buen proyecto para frenar el

${ }^{15}$ Esta apreciación no excluye la referencia de la legación al respaldo del gobierno estadunidense a incursiones en territorio mexicano por parte de filibusteros, como el caso de William Walker, o de indios. Caso excepcional es la duda de Gabriac de que F. Pierce, entonces presidente de Estados Unidos, estuviera respaldando a W. Walker. expansionismo de Estados Unidos en la frontera. Sin embargo, Raousset amplió los planes y decidió impulsar la independencia de Sonora con el respaldo de aventureros estadunidenses y franceses residentes en California, hecho que causó el repudio mexicano. ${ }^{16}$

El apoyo de Levasseur a Raousset puso en peligro las relaciones francomexicanas y provocó su destitución en junio de 1853. Además, las transformaciones que vivía Francia en su situación interna también se reflejarian en su política exterior. El 2 de diciembre de 1851, Luis Napoleón dio un golpe de Estado a la Asamblea y controló el gobierno republicano; exactamente un año después, como resultado de un plebiscito, el príncipe presidente dejaba este título para asumir la dirección del Segundo Imperio, dando un giro a su gabinete $y$ a su política exterior. ${ }^{17}$

Por su parte, Dano, quien sustituyó a Levasseur, no aclaró satisfactoriamente los verdaderos intereses de Raousset y su postura resultó más bien confusa. En efecto, no definió si Raousset tenía el respaldo de Estados Unidos al organizar su empresa desde San Francisco, o si se proponía actuar en contra de las ambiciones expansionistas de los estadunidenses al aceptar la propuesta de Santa Anna de colonizar con franceses la región y formar con ellos una legión que resguardaría de cierta forma la zona fronteriza. Lo que sí queda claro en

${ }^{16}$ Diferentes estudios han mostrado los nexos de Levasseur con la empresa, a pesar de la postura mesurada que mostró en sus despachos. Suárez, Duque, 1990, pp. 15-28; Trueba, Aventurero, 1957, passim.

${ }^{17}$ Sauvigny, Histoire, 1977 , pp. 352-355. 
los despachos de Dano es que trató de no comprometer a la legación y a su país.

Lo sobresaliente del asunto Levasseur-Raousset puso de manifiesto los intereses de un representante diplomático en un asunto de negocios privados con miras a fraccionar el territorio nacional y que ponía en riesgo las relaciones de su país con México y hasta con Estados Unidos.

\section{Caciques}

El segundo caso es el de Santiago Vidaurri, cacique y gobernador del norte de México. Su dominio de los territorios fronterizos le permitió desarrollar nexos comerciales independientes en Estados Unidos. De hecho, fue durante la misión de Gabriac cuando este personaje adquirió importancia en la vida política de México. ${ }^{18}$

Gabriac siempre desconfió de Vidaurri, al considerarlo el prototipo del cacique regional que negociaba con los estadunidenses, que apoyaba las incursiones filibusteras y robaba al erario. Consideraba sumamente peligrosas las ambiciones de este rebelde que, según él, buscaba declarar la independencia de las entidades que dominaba para luego anexarlas a la Unión. El repre-

\footnotetext{
${ }^{18}$ Vidaurri, bajo la bandera liberal, se levantó en armas contra el gobierno de Santa Anna en 1855 y llegó a controlar Nuevo León, Coahuila y parte de Tamaulipas, lo cual le permitió apoderarse de ingresos federales por medio de las aduanas fronterizas. Años más tarde, esto le ge. neró problemas con los gobiernos de Juan Álvarez, Ignacio Comonfort y Benito Juárez. Cerutti, "Poder", 1981, pp. 67-133.
}

sentante francés caracterizaba el caso como un claro ejemplo de los peligros del federalismo y de sus nexos con los planes expansionistas de Estados Unidos. $^{19}$

A diferencia de Levasseur y Dano, y pese a su interés por fortalecer la frontera, Gabriac rechazó la realización de proyectos de colonización porque temía que se filtraran en ellos aventureros que promovieran rebeliones y la independencia de territorios asequibles posteriormente para Estados Unidos. ${ }^{20}$

Así, la legación francesa vio la frontera mexicano-estadunidense bajo una óptica distinta a la que se manejaba en la diplomacia entre ambos países. La legación no se limitó a describir los mecanismos más conocidos y temidos del expansionismo territorial hacia México: colonización, compra o invasión de zonas fronterizas, sino que se adentró en ellos. En el caso de Levasseur, intereses privados se mezclaron con proyectos que de alguna forma planteaban la anexión de Sonora a Estados Uniclos, asunto controversial si se piensa en el temor francés ante un acontecimiento de tal envergadura. Gabriac, por su parte, percibió en la actitud independen-

${ }^{19}$ Gabriac al MaEF, México, 5 de septiembre de 1855 en Díaz, t. 1, p. 200

${ }^{20}$ Cabe señalar que durante los años de 1852 a 1854, paralelamente a los proyectos de Raousset de Boulbon, representantes de México en París negociaron, a través de autoridades francesas, la posibilidad de introducit colonos suizos y demás europeos en la frontera con Estados Unidos para frenar las incursiones de indios y aventureros. Este proyecto no se concluyó. Archivo Histórico de la Secretaría de Relaciones Exteriores de México (en adelante AHSREM), Archivo de la Embajada de México en París, leg. 33, exp. 413, docs. 12515-12571. 
tista de Vidaurri un mecanismo interno, no exclusivamente de Estados Unidos, que tenía el objetivo de fracturar una parte del territorio mexicano para luego anexarse a Estados Unidos.

\section{La Mesilla}

El Tratado de La Mesilla fue un asunto de la frontera que la legación francesa trató poco y sin profundidad. Levasseur casi no lo mencionó y Dano, quien rechazaba de manera sistemática todo lo estadunidense, hizo una excepción en este caso. Informó a su gobierno que consideraba el acuerdo como algo positivo para México y Estados Unidos: México no podía hacer nada ante la amenaza estadunidense y a través del convenio se aseguraba, por lo menos, no perder más que la franja de La Mesilla, y comprometía a su vecino del norte a desistir de otras ambiciones territoriales. Por su parte, Estados Unidos se apoderaba de una región mexicana por la vía legal y pacífica. ${ }^{21}$ No obstante, cuando el tratado se envió a Estados Unidos para su ratificación y se le hicieron algunas modificaciones, $\mathrm{Da}$ no se preocupó por que el gobierno de Santa Anna aceptara cualquier propuesta a cambio de dinero. ${ }^{22}$

Para Gabriac el asunto de La Mesilla no tuvo gran importancia. Se limitó a resaltar que las reclamaciones de los estadunidenses estipuladas en el convenio eran exageradas, y a denunciar

${ }^{21}$ Dano al Maff, México, 3 de enero de 1854 en Díaz, t. 1, p. 87.

${ }^{22}$ Dano al maef, México, 31 de mayo de 1854 en Díaz, t. 1, pp. 113-115. los nexos que James Gadsden, ministro de Estados Unidos en México, tenía con los liberales, al favorecer el pago por La Mesilla a este sector. ${ }^{23}$

\section{EL PASO INTEROCEÁNICO POR TEHUANTEPEC}

La construcción de un paso interoceánico en América era uno de los proyectos más importantes para el comercio mundial: Panamá, Nicaragua, Honduras y México ofrecían opciones viables. Las principales potencias decimonónicas se preocuparon por conseguir concesiones de tránsito y asegurarse puntos estratégicos en las posibles vías. Sin embargo, las acciones del Segundo Imperio en este sentido fueron escasas en comparación con las maniobras de Estados Unidos e Inglaterra. ${ }^{24}$

${ }^{23}$ Para 1856, Estados Unidos todavía debía 3000000 por la compra de La Mesilla; pero Santa Anna, en 1853, ante su necesidad imperiosa de dinero, pidió prestado a especuladores teniendo como garantía este monto faltante. Cuando la Unión decidió cubrir esta suma, Gadsden abogó para que se pagara directamente al gobierno de Comonfort y no a los tenedores de bonos. Gabriac al MAEF, México, 1 de enero de 1856 en Díaz, t. 1, p. 253.

${ }^{24}$ No obstante esta inactividad, cabe apuntar el interés personal de Napoleón III por la construcción de un paso transístmico en Nicaragua. Estando preso en Ham, por órdenes de luis Felipe de Orleans, Napoleón aceptó la propuesta nicaragüense de presidir la construcción de un canal y escribió un folleto al respecto, alabando los beneficios económicos que traería a esa nación y cómo detendría al expansionismo de Estados Unidos. Ya en el poder, Napoleón no olvidó su plan centroamericano, ya que en 1849 autorizó a la Revue Britannique traducir y publicar su folleto sobre Nicaragua. Schefer, Orígenes, 1963, pp. 20-21, 28, 30-31. 
A pesar de que el paso por Tehuantepec, al igual que La Mesilla, era un aspecto significativo de las relaciones México-Estados Unidos, la legación francesa lo abordó sin profundidad. Cada uno de los ministros lo percibió desde distintos ángulos.

Levasseur consideró el proyecto sumamente arriesgado para cualquier inversionista y celebró que ciudadanos franceses no se hubieran involucrado en él. Por otro lado, tal vez respondiendo a su espíritu empresarial, juzgó que la concesión otorgada a principios de 1853 a la Compañía Mixta, de mexicanos y estadunidenses, era un buen paso para México: finalmente se deshacía de la Compañía de Nueva Orleans, conformada principalmente por inversionistas de la Unión y por De Garay, quien era dueño original del privilegio; además cedía el libré tránsito a las naciones que garantizaran la neutralidad del paso, oportunidad que Francia bien podría aprovechar. ${ }^{25}$

Para Dano, el tratado de La Mesilla concedía demasiado a los estadunidenses sobre el istmo mexicano, aunque no remarcó en qué sentido. ${ }^{26}$ Fue sin embargo Gabriac, quien percibía de manera más global, no por eso limitada, el problema del paso transístmico por Tehuantepec, al considerar que el desarrollo industrial en Europa y el comercio con América, China y Australia, requería con urgencia de "una salida para el excedente de nuestros productos fabricados, así como para nues-

\footnotetext{
${ }^{25}$ Levasseur al MAEF, México, 28 de febrero de 1853 en Díaz, t. 1, pp. 22-23.

${ }^{26}$ Dano al MAef, México, 31 de mayo de 1854 en Díaz, t. 1, p. 114.
}

tra población flotante". ${ }^{27}$ Para Gabriac, el paso por Tehuantepec se convirtió, más que en una necesidad comercial para Europa, en punto clave del expansionismo estadunidense y de la anexión de México a esta república. Señaló dos mecanismos mediante los cuales Estados Unidos podría apoderarse de dicha ruta: que expediciones organizadas en Nueva Orleans partieran a la conquista de Tehuantepec, o la cesión pacífica, por medio de un convenio, a cambio de dinero o apoyo político. Sin embargo, contra la visión de Levasseur y su espíritu antiestadunidese, en agosto de 1856 Gabriac reconoció a Peter A. Hargous, presidente de la Compañía de Nueva Orleans, como "el verdadero concesionario del privilegio" del paso por Tehuantepec. ${ }^{28}$ Resulta peculiar esta declaración tomando en cuenta las controversias en México sobre la legitimidad de la concesión a Hargous, y los derechos de la Compañía Mixta que parecía responder a las expectativas francesas de liberar del monopolio de Inglaterra y Estados Unidos a las posibles rutas transístmicas. Al parecer esta postura de Gabriac se debió a sus nexos con Bellangé, negociante francés, apoderado de Hargous, y quien escribió un reporte sobre el asunto de Tehuantepec. ${ }^{29} \mathrm{La}$ inclinación de Ga-

${ }^{27}$ Gabriac al MaEF, México, 6 de junio de 1855 en Díaz, t. 1, p. 190.

${ }^{28}$ Gabriac al MAEF, México, 25 de agosto de 1856 en Díaz, t. 1, pp. 317-318.

${ }^{29}$ Resulta interesante comentar que Gabriac introdujo en sus despachos una copia del documento titulado "Nota relativa a la apertura de una vía de comunicación interoceánica por el istmo de Tehuantepec" escrito por Bellangé en julio de 1856 para ser remitido a la "comisión 
briac por la Compañía de Tehuantepec se desvaneció con la visita, en agosto de 1857, de Judah P. Benjamin, agente de la empresa, evento que lo alertó sobre las desventajas para Fran. cia y el resto de Europa de no tener presencia en ninguna ruta interoceánica en América y el dominio de Estados Unidos sobre todas éstas.

Pese a las advertencias de Gabriac sobre estos peligros, el gobierno francés no apoyó a un empresario francés, apellidado Belly, quien a principios de 1858 obtuvo una concesión para abrir un paso interoceánico en Nicaragua y Honduras; ${ }^{30}$ hasta el propio Gabriac refirió esta empresa como un mero incidente que atentó contra el espíritu estadunidense de la Doctrina Monroe, y exaltó los ánimos mexicanos ante la

revisora del proyecto". Gabriac al MAEF, México, 30 de noviembre de 1856 en Díaz, t. 1, p. 374; Gabriac al MAEF, México, 25 de agosto de 1856, t. 1, pp. 370-374.

${ }^{30}$ La empresa de Belly era de carácter privado y no recibió el apoyo oficial del Ministerio de Asuntos Extranjeros de Francia, pero sí de Napoleón. Schefer en Los origenes señala un aspecto interesante en la política exterior francesa: una diferencia entre la politica del Ministerio de Asuntos Exteriores y la del emperador. Los asuntos que Napoleón III no creía de suma importancia los relegaba al ministro de Asuntos Exteriores; pero cuando la cuestión le era relevante, él la resolvía a su manera. Para Schefer, esta conducta del emperador explica en gran medida su obstinación del plan mexicano y cómo pasaba por alto datos que no concordaban con sus deseos. La imposibilidad de consultar las instrucciones del MAEF a la legación en México nos impide verificar esta interpretación, aunque sí podemos encontrar nexos importantes entre los acontecimientos franceses y las líneas políticas de los ministros galos. Schefer, Origenes, 1963, p. 27. posibilidad de un enfrentamiento entre Francia y la potencia americana.

De esta forma, la legación francesa detectó dos peligros en esa posesión del paso interoceánico en Tehuantepec: el control de la potencia norteña del comercio en zonas estratégicas, y la posible anexión del istmo a Estados Unidos, dando pie a la absorción total de México.

\section{CUESTIÓN DE BIENES, CUESTIÓN DE FE}

La instauración en Francia de la Segunda República, resultado de la radical revolución de 1848, motivó a los notables a buscar en la Iglesia un aliado político que sirviera para controlar al pueblo. Ésta a su vez, veía en Luis Napoleón Bonaparte, entonces dirigente de la República, el salvador de la amenaza socialista y atea e indudablemente un "mal menor". 31

La buena relación entre la Iglesia y el Estado en Francia sirvió a Luis Napoleón para consolidar sus pretensiones imperiales. ${ }^{32}$ Ya coronado, Napoleón III trató de implantar una política aparentemente liberal pero que en el fondo tenía fuertes matices conservadores y reconoció a la Iglesia como un importante aliado de su régimen. Le

${ }^{31}$ Robert, XIXe, 1995, t. 1, p. 291; Grenville, Europa, 1980, pp. 141-142.

${ }^{32}$ Napoleón III restituyó a Pío IX en los Estados Papales (1849) y apoyó a Italia en su lucha contra Austria. Cabe resaltar que Francia pretendía derrotar a Austria, a la vez que pactar con el movimiento republicano italiano, pero sus compromisos con el papado se lo impidieron y, por el contrario, favoreció al dominio del clero. Grenville, Europa, 1980, pp. 137, 300. 
ofreció influencia y riqueza, a cambio de fomentar entre el pueblo el amor por su emperador. ${ }^{33}$

Conociendo este contexto es más fácil interpretar la postura de Levasseur, Dano y sobre todo de Alexis de Gabriac frente a la Iglesia en México. Los dos primeros reconocieron en esta institución la base económica y moral del Estado mexicano; pero sólo Levasseur hizo una reflexión peculiar al respecto: uno de los mecanismos más efectivos para frenar el expansionismo de Estados Unidos era la estabilidad política de México, y para lograrla, la Iglesia era una institución fundamental y por tanto intocable.

Por su parte, Gabriac reconoció la importancia del clero en la realidad mexicana a raíz de las Leyes de Reforma, resaltando sus repercusiones a nivel nacional e internacional. Durante sus primeros años en la legación (18531856), Gabriac cuestionó el peso de la Iglesia en la política y economía mexicanas; pero tras el advenimiento del ala liberal al poder en 1856, apoyó a la institución eclesiástica debido a la relación que hizo de las leyes anticlericales con la amenaza estadunidense.

La desamortización de los bienes del clero generaba inquietud. ¿En manos de quién quedarían aquellas riquezas? Si México llevaba años postrado en una profunda crisis económica, la imperante necesidad de recursos de los distintos gobiernos facilitaría algún mecanismo para posesionar a Estados Unidos de las tierras del clero mexi-

\footnotetext{
${ }^{33}$ No obstante sostuvo algunos principios revolucionarios como la libertad de cultos. Grenville, Europa, 1980, p. 215.
}

cano. Así, Gabriac refería alarmado los rumores de que, en nombre de su gobierno, James Gadsden otorgaría un préstamo de 20000000 de dólares a los "puros", teniendo como garantía los bienes de la Iglesia. Sobre este último punto, el ministro francés señaló que México nunca podría pagar tal empréstito, lo que ocasionaría su ruina y su anexión a Estados Unidos, porque "pondría a disposición de los yanquis casi la mitad de las propiedades rurales de la república", 34

Otra inquietud eran los posibles nexos de los estadunidenses con el proyecto de Reforma para fomentar la creciente "anarquía" en México, resquebrajar a la república y apoderarse de nuevos territorios. Acerca del proyecto de Constitución de 1857, Gabriac concluyó que era el más fiel testimonio "de la influencia disolvente con que operan los yanquis". ${ }^{35}$

Cuando se aprobaron las modificaciones contra el fuero y bienes eclesiásticos, el ministro francés consideró que se facilitaban nuevos medios de expansión a las ambiciones estadunidenses. En este sentido, Gabriac aprovechó sus críticas a la política anticlerical del gobierno como una forma de combatir las ambiciones de la Unión.

Pero la amenaza estadunidense a la Iglesia no se limitó a lo material, pues se refería también a la cuestión de fe. Gabriac fue el único en reconocer que la tradición, las lenguas y las costumbres permitían definir la nación mexi-

\footnotetext{
${ }^{34}$ Gabriac al MaEF, México, 1 de abril de 1856 en Diaz, t. 1, p. 265.

35 Gabriac al MaEF, México, 28 de mayo de 1856 en Díaz, t. 1, p. 290.
} 
cana, pero el catolicismo era "la única y más poderosa barrera que existía en México contra la ola invasora de los yanquis, ateos y mormones", ${ }^{36}$ era el lazo que mantenía unido a México, impedía que se desmoronara e imposibilitaba la anexión a Estados Unidos.

Gabriac narró constantemente las desavenencias entre la Iglesia y el go. bierno liberal, así como la posible expulsión del delegado del Vaticano en México, monseñor Luis Clementi, por su oposición a las leyes en contra del clero, hecho que el francés trascendió a ámbitos internacionales: decía que si por la "perfidia" de Gadsden en torno a Clementi y las Leyes de Reforma se rompían las relaciones diplomáticas entre México y el Vaticano, Francia tomaría cartas en el asunto, debido a sus compromisos con su santidad, hasta el grado de pensar en un enfrentamiento con Estados Unidos. ${ }^{37}$ Y completaba su argumentación diciendo que era preci-

\footnotetext{
${ }^{36}$ Gabriac al MAEF, México, 5 de abril de 1856 en Díaz, t. 1, p. 269.

${ }^{37}$ En este sentido llegó a comparar la intromisión de Estados Unidos en la fe y la Iglesia mexicana con la ocupación rusa en Constantinopla y el Santo Sepulcro. Según capitulaciones del siglo XVI entre Francisco I y Solimán el Magnífico, Francia tenía el derecho de proteger a los establecimientos cristianos en Oriente. En 1850 el gobierno turco reconoció los derechos de Francia y ésta llegó a un acuerdo diplomático con Rusia (1851). Pouthas, Politique, 1952, pp. 68-69. Por otro lado, valdría tomar con tiento la amenaza de una guerra franco-estadunidense, ya que en 1856 Francia todavía tenía compromisos militares en Oriente. Tal vez esta aseveración pretendía resaltar la amenaza estadunidense para México, sus enormes consecuencias y comprometer al país galo. Gabriac al MAEF, México, 5 y 11 de abril de 1856 en Díaz, t. 1, pp. 269, 271.
}

samente Francia y ninguna otra potencia la que tenía la responsabilidad de impedirlo:

En relación al problema mexicano $[\ldots]$ Francia sería atraida tanto por [intereses materiales] como por los intereses políticos y religiosos de primer orden. Sin duda nos importa mucho que Estados Unidos subsista, pero en condición de pais auxiliar inferior, jamás de amo. Creando a su lado una nueva potencia que nos dé una mayor fuerza, le pon. dríamos un freno regulador. ${ }^{38}$

De esta forma, la percepción de la legación sobre la relación Iglesia-Estado y la religión católica en México estuvo estrechamente vinculada con dos temas: los nexos del Segundo Imperio francés con el Vaticano y la amenaza estadunidense.

\section{SOLUCIONES AL. EXPANSIONISMO DE ESTADOS UNIDOS}

A lo largo de los años 1853 a 1860 las soluciones propuestas por la legación francesa para detener el expansionismo estadunidense en México fueron intensificando su carácter agresivo e intervencionista.

Levasseur sugirió tímidamente el fortalecimiento político y económico de México a través de un gobierno dictatorial y centralista que fuera capaz de eludir las provocaciones de los estadunidenses. Así, limitaba la ayuda francesa a proyectos de colonización y a la intermediación en caso de conflic-

${ }^{38}$ Gabriac al MAEF, México, 7 de octubre de 1856 en Díaz, t. 1, p. 344. 
to entre los dos países del norte de América. Levasseur llegó a aclarar a los mexicanos que pedían la ayuda francesa, que su país no estaba dispuesto a arriesgar sus relaciones y comercio con Estados Unidos por apoyar sus demandas. ${ }^{39}$

Al inicio de su labor, Dano vislumbró un protectorado europeo, aunque no español, como respuesta a la situación mexicana y a las amenazas de Estados Unidos; pero sus ideas fueron cambiando, sobre todo a raíz del incidente de Raousset de Bourbon, ya que meses después propuso el establecimiento de una monarquía europea que gobernara a México, "país incapacitado totalmente para solucionar sus dificultades". ${ }^{40}$

Gabriac, no en balde claro representante del Segundo Imperio, mostró contundente en sus despachos sus principios expansionistas. Consideraba que la única salida para los problemas mexicanos y la amenaza estadunidense era la instauración de una monarquía europea: Napoleón III tenía la fuerza para hacerlo y desafiar a la Doctrina Monroe. ${ }^{41}$ Además, justificó sus opiniones en la solicitud de importantes personalidades mexicanas: "Este pueblo [dijo] está hecho más para un gobierno teocrático-monárquico que cualquier otro." ${ }^{42}$ Prueba de estas convicciones era su

\footnotetext{
39 Levasseur al MAEF, México, 31 de abril de 1853 en Díaz, t. 1, p. 47.

${ }^{40}$ Dano al MaEF, México, 18 de julio de 1853 y 24 de octubre de 1853 en Díaz, t. 1, p. 57 y pp. 68-71.

${ }^{41}$ Gabriac al MaEF, México, 26 de julio de 1856 en Díaz, t. 1, p. 312.

42 Gabriac al MAEF, México, 9 de septiembre de 1856 en Díąz, t. 1, p. 313.
}

conocida amistad con el marqués de Radepont y su apoyo al "Proyecto para la regeneración de México", fracasado plan monarquista para llevar a gobernar a México al príncipe de Aumale, hijo de Luis Felipe de Orleans. ${ }^{43}$ Para Gabriac el antiguo régimen era la única manera de derrotar a Estados Unidos; no era ni "por una invasión ni por una guerra directa como se le puede reducir, sino por el camino de México". ${ }^{44}$

A través de los años, las soluciones propuestas por los ministros incrementaron su hostilidad, probablemente por la situación de Francia, así como por sus crecientes intereses económi. cos y políticos en México y en la región. Cabría añadir que los problemas internos y la política exterior de Estados Unidos también influyeron en las acciones de la legación.

\footnotetext{
${ }^{43}$ Aimé Louis Leon de Bosc, marqués de Radepont, dejó, en 1847 , la representación francesa ante Washington para ir a México con el fin de vigilar los derechos de sus conciudadanos a la luz de la guerra. Después de la pérdida territorial mexicana, Radepont se empeñó en establecer una monarquía europea en dicho pais y consecuentemente en toda América Latina para frenar el expansionismo estadunidense. Apoyado por Gabriac y conservadores mexicanos, a principios de 1856 viajó a Francia para presentar sus planes a Napoleón III, quien no lo recibió. Ante esta negativa acudió a George Clarendon, ministro de asuntos extranjeros de Gran Bretaña, sin éxito alguno. En noviembre del mismo año consiguió casualmente una entrevista con el emperador francés resaltando la amenaza de la Unión sobre los posibles pasos interoceánicos en América; al parecer este en cuentro influyó en los planes franceses. Jackson, Napoleón, 1973, pp. 19-24; Barker, "French Legation", [1979], p. 410.

${ }^{44}$ Gabriac al MAEF, México, 11 de noviembre de 1856 en Díaz, t. 1, p. 365; Gabriac al MAEF, México, 1 de julio de 1856 en Díaz, t. 1, p. 304.
} 


\section{PARA CONCLUIR}

El hecho de que Levasseur, Dano y Gabriac fueran los representantes de dos sistemas de gobierno distintos en Francia (una república y un imperio), vivieran momentos distintos de la historia mexicana y estadunidense, y tuvieran convicciones políticas diferentes, no fue determinante para que su visión sobre el expansionismo estadunidense variara radicalmente. Sucede, por el contrario, que visualizaron a ese expansionismo estadunidense a través de procesos similares: del desarrollo mundial del capitalismo, de la situación interna de México, de la importancia de salvaguardar la frontera norte de México, del paso interoceánico por el istmo de Tehuantepec, de la Iglesia y de la religión católica. Tal coincidencia de temas y enfoques conforman una unidad, que probablemente explique las pretensiones de Luis Napoleón Bonaparte hacia México, ya fuera como pre. sidente de una república o como emperador, ${ }^{45}$ y las líneas de la política exterior estadunidense, la cual no varió en lo fundamental durante los años de 1853 a 1860.

No obstante, dentro de dicha unidad se puede observar una evolución. Los intereses de Francia por aumentar su presencia e influencia económica y política en América, concretamente en

\footnotetext{
${ }^{45}$ Desde la presidencia de la república, Napoleón Bonaparte determinó su política como emperador: informarse de los asuntos estadunidenses, mexicanos, centroamericanos y caribeños; mantener un comercio activo con la región, impulsar la migración de ciudadanos franceses a la misma y guardar relaciones diplomáticas cordiales.
}

México, encaminaron sus acciones para preparar el terreno de la intervención en dicho país. En este argumento, el expansionismo de Estados Unidos era una clara preocupación y motivo de sus planes mexicanos, pero sirvió también como justificación. La visión de la legación sobre Estados Unidos refleja a su manera estos cambios. De esta manera, la percepción de su expansionismo por la legación francesa entre los años de 1853 y 1860 resulta similar a un embrión: una unidad que crece y se define hasta conformar algo mayor. La hija caprichosa de Napoleón III: la intervención francesa en México.

\section{ARCHIVOS}

AHSREM Archivo Histórico de la Secretaría de Relaciones Exteriores de México.

\section{BIBLIOGRAFÍA}

-Barker, Nancy, "The french legation in Mexico: nexus of the intervensionism", French Historical Studies, núm. 8, pp. 409-426. , The french experience in Mexico, 1821-1861: a bistory of constant misunderstanding, University of North Carolina Press, Chapel Hill, 1979.

- Bertier de Sauvigny, G. de, Histoire de France, Flammarion, Francia, 1977.

-Cerutti, Mario, "Poder estatal, actividad económica y burguesa regional en el noreste de México, 1855-1910", Siglo XX. Revista de Historia, núm. 1, pp. 67-133.

-Díaz, Lilia (comp.), Versión francesa de México. Informes diplomáticos, El Colegio de México, México, 1963-1967, 4 vols.

-Friedenson, Patrick y André Straus, Le capitalisme français, 10-20 siécle, bloca- 
ges et dynamismes d'une crossance, Fayard, París, 1987.

-González Navarro, Moisés, Los extranjeros en México y los mexicanos en el extranjero, 1821-1970, El Colegio de México, México, 1993, 3 vols.

-Grenville, J. A. S., La Europa remodelada, 1848-1878, Siglo XXI, México, 1980 (Historia de Europa).

-Hanna, Alfred y Kathryn Abbey Hanna, Napoleón III y México, Fondo de Cultura Económica, México, 1973 (Obras de Historia).

-Meyer, Jean, Francia y América. Del siglo XVI al siglo XX, Mapfre, España, 1992.

-Pérez Siller, Javier, México Francia. Memoria de una sensibilidad común siglos $X I X-X X$, UAP/El Colegio de San Luis/CEMCA, México, 1998.
-Pouthas, Charles Hippolyte, Les politiques etrangeres de la France sous le seconde republique et le second empire, Centre de documentation Universitaire, París, 1949 (Les Cours de la Sorbonne).

-Robert, J. L., Le XIX siècle, Breal, París, 1995.

-Schefer, Christian, Los origenes de la intervención francesa en México (18581862), Porrúa, México, 1963.

-Suárez Argüello, Ana Rosa, Un duque norteamericano para Sonora, CONACULTA, México, 1990 (Regiones).

-Tulerand, Jean, Dictionnaire du Second Empire, Fayard, París, 1995.

-Trueba, Alfonso, Aventurero sin aventura (Gastón de Raousset), Jus, México, 1957 (Figuras y Episodios de la Historia de México, 10). 


\section{SECUENCIA}

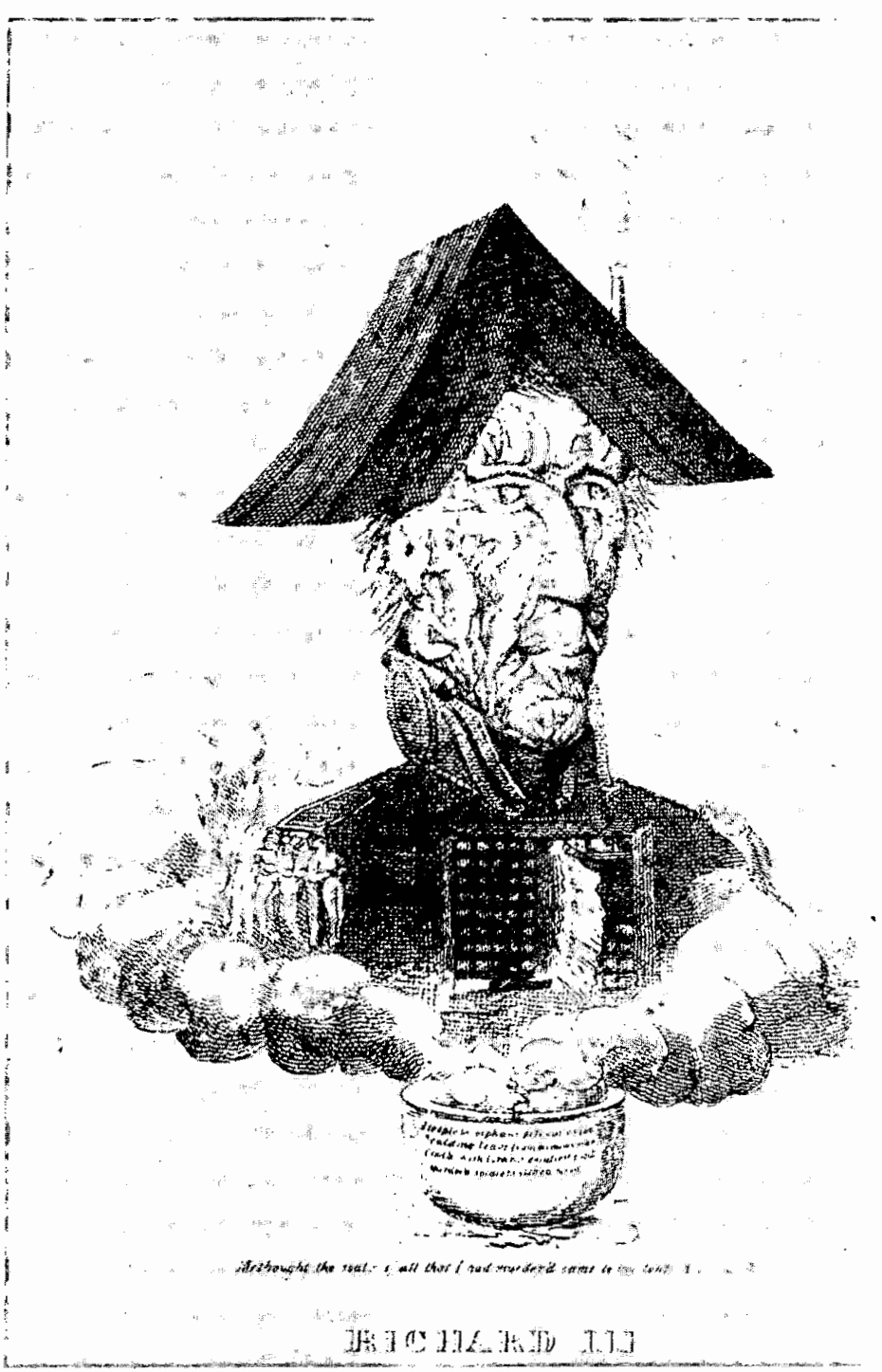

